\title{
Bienvenue de la présidente
}

\section{Reine Malouin}

Volume 36, 1969

URI : https://id.erudit.org/iderudit/1007290ar

DOI : https://doi.org/10.7202/1007290ar

Aller au sommaire du numéro

Éditeur(s)

Les Éditions Historia Ecclesiæ Catholicæ Canadensis Inc.

ISSN

0318-6172 (imprimé)

1927-7067 (numérique)

Découvrir la revue

Citer ce document

Malouin, R. (1969). Bienvenue de la présidente. Sessions d'étude - Société

canadienne d'histoire de l'Église catholique, 36, 11-12.

https://doi.org/10.7202/1007290ar

Tous droits réservés @ Les Éditions Historia Ecclesiæ Catholicæ Canadensis Inc., 1970
Ce document est protégé par la loi sur le droit d'auteur. L'utilisation des services d'Érudit (y compris la reproduction) est assujettie à sa politique d'utilisation que vous pouvez consulter en ligne.

https://apropos.erudit.org/fr/usagers/politique-dutilisation/ 


\section{Bienvenue de la présidente}

Si c'est mon privilège de présider à l'ouverture de ce congrès en vous souhaitant la plus cordiale bienvenue, croyez que je le fais avec une véritable joie. Il en est un autre que j'apprécie grandement, c'est celui de pouvoir présenter les hommages de tous les membres de notre Société à son Eminence le cardinal Maurice Roy, archevêque de Québec et Primat de l'Église canadienne, qui a bien voulu accorder son distingué patronage à ces assises et, par surcroît, nous déléguer $\mathbf{M g r}$ Ernest Lemieux, que nous considérons comme un des intellectuels les plus raffinés de son temps.

L'honorable ministre des Affaires culturelles, monsieur Jean-Noël Tremblay, en plus de nous offrir une aide efficace, a tenu à se faire représenter par le ministre d'État à l'Éducation, M. Jean-Marie Morin; c'est donc la province de Québec qui s'unit à nous pour vous accueillir dans ce Vieux Monastère dont l'hospitalité nous est gracieusement offerte par les Dames Ursulines de Québec.

Depuis sa fondation, en 1933, la Société canadienne d'Histoire de l'Église catholique organise un congrès annuel au cours duquel divers spécialistes sont appelés à nous faire part de leurs recherches sur quelques aspects de l'histoire religieuse de notre pays.

Au moment où tant de controverses, voire de critiques plus ou moins fondées se produisent au sujet des communautés religieuses, nous avons cru opportun de les remettre nous aussi en question, afin de sonder les raisons fondamentales de leur venue, la valeur de leur démarche et l'orientation de leur action en terre québecoise.

Pour nous situer au cœur de l'histoire du XIX' siècle, un aspect général sur les communautés (1837-1914) sera évoqué, ensuite nous tenterons de mieux comprendre les causes déterminantes de leur établissement chez nous. Certes, ces quelques communautés, que nous avons l'avantage de vous présenter, ne sont pas les seules à avoir contribué à l'évolution de notre histoire; nous avons dû forcément nous limiter, laissant aux chercheurs le soin de poursuivre le travail amorcé à ce congrès. Nous souhaitons seulement que ces études dissipent quelques préjugés, s'il y a lieu, en replaçant chacune des communautés mentionnées dans le contexte historique.

Nous qui œuvrons dans le domaine de l'Histoire, nous avons constaté que les problèmes religieux, psychologiques ou humains sont de 
plus en plus aigus. Clercs et laïcs marquent l'angoisse qui caractérise notre période d'évolution actuelle. En ce moment, nous taillons le travail des futurs historiens, car, de nos jours, tout est contesté, à tort ou à raison. La vie du clergé, comme celle des communautés religieuses ou des laïcs catholiques, est devenue - je devrais dire reste - une lutte constante et douloureuse, de laquelle nous ne sortons pas toujours triomphants.

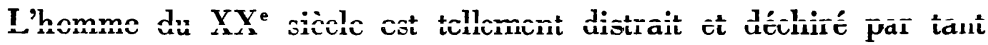
d'événements spectaculaires, qu'il en oublie l'essence même de la vie de l'homme : sa spiritualité. Il est utile, nécessaire même, de nous rappeler quelques vérités, vues à la lumière des dons reçus jadis par ceux qui ont vécu en communautés et qui nous ont fait le don d'eux-mêmes.

Lorsque nous construisons un grand édifice, un barrage, un pont, les ingénieurs ne trouvent-ils pas obligatoire de faire périodiquement le sondage des piliers déjà construits, avant d'ajouter ou de parfaire la construction? L'approche qui se fera au cours de ces séances d'étude en est une de connaissance des faits, de mouvements d'âmes, de qualifications des actes posés jadis, qui aideront à la compréhension d'une époque.

Ce que la foi éclairante de 1850 a été capable d'accomplir dans un climat social souvent difficile; ce qu'elle portait en elle de feu et de vérité, tout cela sera rappelé dans la simplicité des faits situés dans le contexte historique du XIX ${ }^{e}$ siècle. Ce sera comme une vérification des piliers qui ont soutenu notre édifice social et religieux. Ce sondage ne sera pas inutile, il contribuera à rééquilibrer nos pensées, au moment, surtout, où le $\mathrm{XX}^{\bullet}$ siècle en ébullition s'apprête à nous reconditionner dans un environnement spirituel absolument repensé et nouveau.

La présidente,

Reine Malouin. 